\title{
El Régimen jurídico de la prestación por desempleo en el ordenamiento español
}

CARMEN VIQUEIRA

La gravedad del fenómeno del desempleo está, sin duda, presente en la conciencia social, sobre todo en nuestro país que ostenta la tasa de paro más alta y la tasa de actividad más baja de Europa. Por lo demás, el problema del desempleo ha sido acometido, por lo que a la política social se refiere, en torno a dos líneas de actuación. Por una parte, procurando la creación de empleo, y, por otra facilitando protección frente a la situación de necesidad que el desempleo genera. La dificultad constatada que conlleva la primera línea apuntada hace que aumente, para los trabajadores y para los operadores jurídicos, la importancia de la protección otorgada por la Seguridad Social.

El trabajo analiza pormenorizada y unitariamente el régimen jurídico de la más genuina de las medidas previstas en el sistema español de la Seguridad Social con aquella finalidad: la prestación por desempleo en el nivel contributivo de la protección.

La reforma legislativa operada en 1984 mediante la promulgación de la Ley de Protección por Desempleo, si bien no ha supuesto un cambio radical en el tratamiento tradicional del tema, sí ha venido a alterar, sin embargo, numerosos y fundamentales aspectos de la normativa precedente. Este hecho, unido a la novedad de la regulación normativa y a la ausencia de trabajos de investigación con un tratamiento unitario y completo, así como de líneas jurisprudenciales asentadas, justifica, sobradamente, el estudio de un tema que se ha convertido en objeto permanente de debate en las sociedades occidentales.

Por la propia naturaleza de su objeto, el estudio presenta un contenido netamente jurídico y referido exclusivamente el derecho español. 
Por ello, tras una previa y deliberadamente esquemática reflexión acerca de la configuración del fenómeno del paro, que desemboca en la descripción de los distintos sistemas institucionales de protección, se entra directamente en el examen del régimen jurídico de la prestación.

En contra de lo que a primera vista pudiera parecer, y pese a la sustancial mejora que, por lo que se refiere a técnica legislativa, ha supuesto la Ley de Protección por Desempleo, el régimen jurídico de esta institución plantea multitud de problemas que, contemplados aisladamente, como se ha venido haciendo en relación con alguno de ellos, son de difícil solución por la deficiencia que implica la ausencia de una perspectiva de conjunto de dicho régimen jurídico, dada la interconexión existente entre los diversos aspectos que lo configuran. Ciñéndonos a los problemas fundamentales, huyendo, pues, de una mera descripción lineal del contenido del trabajo, pueden destacarse los siguientes aspectos.

La determinación de los sujetos protegidos ha obligado ha adentrarse en esos «temas límite» entre el derecho del Trabajo y otras disciplinas jurídicas (como, por ejemplo, sucede con los emigrantes retornados o los penados liberados), y ha exigido una labor de clarificación de la muy profusa normativa reguladora de los regímenes especiales. Se obtiene así, frente a la aparente claridad normativa en la delimitación del ámbito de la protección, un complejo panorama no sólo de inclusiones y exclusiones, sino también de gradaciones en cuanto al nivel de efectividad de la cobertura.

Los sujetos incluidos en el ámbito de protección y su determinación ha requerido, por otra parte, que se lleve a cabo una compleja labor de delimitación de la situación legal de desempleo, y, por tanto, el examen pormenorizado de las distintas situaciones que la ley enumera, así como de los medios acreditativos de estas, tras el cual se pone de manifiesto que la nueva normativa, pese a su pretendida exhaustividad, adolece de graves lagunas.

Desde una óptica organicista, se plantea la problemática que conlleva cada una de las fases por las que atraviesa la vida de la prestación desde su nacimiento, procediendo a la clarificación de determinados aspectos procedimentales insuficientemente tratados en la normativa. Cabe 
aqui destacar la tarea de sistematización de las causas de extinción y suspensión, a partir de la Ley de Infracciones y Sanciones en el Orden Social. Se distingue, por un lado, aquellas suspensiones o extinciones que traen su causa de la particular situación del desempleado frente al mercado de trabajo, y, por otro, aquellas otras que tienen una clara naturaleza sancionadora. Con base en esta distinción, se efectúa también el análisis de los muy distintos efectos jurídicos que en cada caso se siguen, en especial, con respecto a la eventual reanudación del derecho a la prestación.

Especialmente clarificadora resulta la construcción que se realiza de una teoría unitaria en orden a la solución de la concurrencia o acumulación de suspensiones, ante la absoluta imprevisión normativa al respecto. Allí, tras realizar un original diseño de la tipología de la acumulación de suspensiones, distinguiendo, por un lado, la acumulación por intersección frente a la acumulación por inclusión, y, por otro, la acumulación homogénea frente a la acumulación heterogénea, se analiza el momento y el modo en que ha de producirse la reanudación del derecho, así como la cuantía y duración de la prestación reanudada.

Tras exponer la dinámica general de las reglas que rigen la determinación de la cuantía y duración de la prestación (esto es, qué cotizaciones son computables, cómo se delimita el período previo de cotización y el período en el cual las cotizaciones deben encontrarse comprendidas), se aborde el tratamiento de aquellas otras prestaciones que podrían calificarse de complementarias de la de desempleo (asistencia sanitaria, abono de cuotas a la seguridad social, acciones específicas de formación, perfeccionamiento, orientación y reconversión profesionales).

Finalmente, se realiza un exhaustivo y pormenorizado estudio de los supuestos de compatibilidad o incompatibilidad de la percepción de esta prestación con la obtención de otras prestaciones de la seguridad social o con el trabajo lucrativo.

La solución de éstas y otras cuestiones constituyen el objeto del trabajo, pero éste no se limita a una mera descripción y resolución de problemas puntuales. De él pueden extraerse consideraciones generales tanto de lege data como de lege ferenda. En este sentido, se denuncia y se 
aprecia a lo largo del trabajo la inadecuación del sistema de protección vigente. Como se sabe, tradicionalmente, la normativa ha venido manteniendo un sistema de protección deudor del más genuino esquema del seguro, y cuya funcionalidad se ciñe a las situaciones de paro friccional, resultando, por tanto, inadecuado para la protección de cualquier otro tipo de desempleo. De aquí que se ponga de manifiesto que la muy distinta configuración del fenómeno del desempleo, caracterizado ahora por su intensidad y por originar situaciones de prolongada permanencia en el tiempo, debiera haber encontrado como respuesta una consecuente remodelación del mecanismo de la protección. 